\title{
Evaluation of enamel surface after bracket debonding and polishing
}

Lilian Maria Brisque Pignatta', Sillas Duarte Júnior², Eduardo César Almada Santos ${ }^{3}$

Introduction: Preserving the dental enamel structure during removal of orthodontic accessories is a clinician's obligation. Hence the search for an evidence based debonding protocol.

Objective: to evaluate and compare, by means of scanning electron microscopy (SEM), the effects of four different protocols of bracket debonding and subsequent polishing on enamel surface, and to propose a protocol that minimizes damage to enamel surface.

Methods: Twelve bovine permanent incisors were divided into four groups according to the instrument used for debonding and removal of the adhesive remnant. In groups 1 and 2, brackets were debonded with a straight debonding plier (Ormco Corp., Glendora, California, USA), and in groups 3 and 4, debonding was performed with the instrument Lift-Off (3M Unitek, Monrovia, California, USA). In groups 1 and 3, the adhesive remnant was removed using a long adhesive removing plier (Ormco Corp., Glendora, California, USA) and in groups 2 and 4, residual adhesive was removed with a tungsten carbide bur (Beavers Dental) at high-speed. After each stage of debonding and polishing, enamel surfaces were replicated and electron micrographs were obtained with 50 and 200X magnification.

Results: All four protocols of debonding and polishing caused enamel irregularities.

Conclusion: Debonding brackets with straight debonding plier, removal of adhesive remnant with a tungsten carbide bur and polishing with pumice and rubber cup was found to be the protocol that caused less damage to enamel surface, therefore this protocol is suggested for debonding brackets.

Keywords: Dental enamel. Scanning electron microscopy. Orthodontics.

${ }^{1} \mathrm{PhD}$ Student of Orhtodontics, Araçatuba Dental School - UNESP.

${ }^{2}$ Associate Professor, Department of Comprehensive Care, Case School of Dental Medicine, Case Western Reserve University, Cleveland, USA.

${ }^{3}$ Associate Professor of Orthodontics, Department of Pediatric and Social Dentistry, Araçatuba Dental School - UNESP.
How to cite this article: Pignatta LMB, Duarte Júnior S, Santos ECA. Evaluation of enamel surface after bracket debonding and polishing. Dental Press J Orthod. 2012 July-Aug;17(4):77-84.

Submitted: July 15, 2010 - Revised and accepted: September 19, 2011

» The authors report no commercial, proprietary or financial interest in the products or companies described in this article.

Contact address: Lilian Maria Brisque Pignatta

R. Presidente Bernardes, 482 - Apto 73 - Santo Antônio - CEP: 16015-353

Araçatuba/SP - Brazil - E-mail: lipignatta@hotmail.com 


\section{Avaliação da superfície do esmalte dentário após a remoção do braquete e polimento}

Lilian Maria Brisque Pignatta', Sillas Duarte Júnior², Eduardo César Almada Santos ${ }^{3}$

Introdução: a preservação da estrutura de esmalte após a remoção dos acessórios ortodônticos é obrigação do clínico. Portanto, procura-se um protocolo de descolagem com bases científicas.

Objetivo: objetivou-se avaliar por microscopia eletrônica de varredura (MEV) a influência de quatro protocolos de remoção de braquetes e polimento da superfície do esmalte e propor um protocolo que minimize os danos à superfície do esmalte.

Métodos: doze incisivos permanentes bovinos foram divididos em quatro grupos de acordo com os instrumentos utilizados para a descolagem dos braquetes e remoção do remanescente adesivo. Os braquetes foram descolados com o alicate de descolagem reto (Ormco Corp.) nos grupos 1 e 2, e com o instrumento de descolagem Lift-Off (3M Unitek) nos grupos 3 e 4 . Os remanescentes adesivos dos grupos 1 e 3 foram removidos com o alicate removedor de resina longo (Ormco Corp.) e dos grupos 2 e 4 com broca de carboneto de tungstênio (Beavers Dental) em alta-rotação. As superfícies, após cada etapa da descolagem e polimento, foram avaliadas em réplicas de resina epóxica e foram obtidas eletromicrografias com aumento de 50 e $200 \mathrm{X}$.

Resultados: os quatro protocolos de remoção de acessórios ortodônticos e polimento ocasionaram irregularidades no esmalte.

Conclusão: a remoção do braquete com o alicate de descolagem reto, seguido da remoção do remanescente adesivo com broca de carboneto de tungstênio e polimento final com pasta de pedra-pomes foi o procedimento que ocasionou menores danos ao esmalte, sendo o protocolo sugerido para a remoção dos acessórios ortodônticos.

Palavras-chave: Esmalte dentário. Microscopia eletrônica de varredura. Ortodontia.

\footnotetext{
${ }^{1}$ Especialista, Mestre e Doutora em Ortodontia pela Faculdade de Odontologia de Araçatuba - UNESP.

${ }^{2}$ Professor Associado, Departamento de Assistência Integral, Case School of Dental Medicine, Case Western Reserve University, Cleveland, EUA.

${ }^{3}$ Professor Adjunto do Departamento de Odontologia Infantil e Social, Disciplina de Ortodontia, FOA-UNESP.
}

\footnotetext{
Como citar este artigo: Pignatta LMB, Duarte Júnior S, Santos ECA. Evaluation of enamel surface after bracket debonding and polishing. Dental Press J Orthod. 2012 July-Aug;17(4):77-84.

Enviado em: 15 de julho de 2010 - Revisado e aceito: 19 de setembro de 2011

» Os pacientes que aparecem no presente artigo autorizaram previamente a publicação de suas fotografias faciais e intrabucais.

» Os autores declaram não ter interesses associativos, comerciais, de propriedade ou financeiros, que representem conflito de interesse nos produtos e companhias descritos nesse artigo.

Endereço para correspondência: Lilian Maria Brisque Pignatta R. Presidente Bernardes, 482 - Apto 73 - Santo Antônio - CEP: 16015-353 Araçatuba/SP - E-mail: lipignatta@hotmail.com
} 


\section{INTRODUCTION}

With the introduction of acid-etch bonding technology by Buonocore, ${ }^{1}$ the direct bonding of brackets became the procedure of choice in orthodontic treatment.

Maximum preservation of enamel surface structure after orthodontic treatment with minimum enamel loss during bracket debonding and polishing is one of the goals of orthodontists. ${ }^{2-5}$ However, the clinical sequence to debond brackets and to remove the adhesive remnant has been empirically proposed, ${ }^{3,6}$ i.e., without a deep scientific investigation on how debonding techniques affect enamel surface. ${ }^{7}$ Enamel damage can be attributed to tooth prophylaxis using abrasive materials, ${ }^{8}$ enamel acid-etching technique, ${ }^{5,8,9}$ enamel fractures caused by bracket debonding, ${ }^{10}$ and removal of residual adhesive with rotary instruments. ${ }^{5,8,11}$

There are few reports in the literature that examined debonding techniques and their effects on the enamel surface., ${ }^{42}$ It is widely known that debonding should not cause enamel irregularities. ${ }^{6}$ such as furrows $^{2,3,13}$ and fractures. ${ }^{14}$ Techniques that promote the union failure at the bracket-adhesive interface are most appropriated, because the adhesive remnant minimizes the risk of enamel loss during debonding.,12

The search for an efficient and safe clinical protocol for removal of residual adhesive after debonding resulted in the introduction of a great variety of instruments and procedures. ${ }^{8,15}$ This procedures including manual removal with curettes and adhesive removing pliers or band removing pliers, ${ }^{2,5,6,8,13,16}$ tungsten carbide burs used at high or low speed, ${ }^{2-7,9,11,13,15,17}$ polishing disks, ${ }^{2,4,7,15,17}$ pumice or zirconia paste, ${ }^{4,7,13,16,18}$ as well as the use of ultrasonic scalers. ${ }^{9,16}$

The presence of remnant resin facilitates plaque build-up, possibly leading to the formation of decalcified areas and caries lesions. ${ }^{6}$ These remnants also can suffer discoloration, jeopardizing esthetics, a highly important factor in orthodontics. ${ }^{6}$

Inadequate procedures can cause enamel loss, ${ }^{11,19}$ altering original tooth morphology with the formation of grooves and facets. ${ }^{19} \mathrm{~A}$ consensual protocol of debonding and removal of adhesive remnant was not yet established, and there is a wide variety of clinical options, without real knowledge about the biologic cost to enamel.

There is a need to establish these procedures with criteria and biological bases, from bracket debonding to final polishing of enamel surface, and the scanning electron microscopy (SEM) allows greater precision in observing and examining enamel surfaces.

Thus being, the present study aimed to evaluate and to compare, by SEM, the effects of four protocols of bracket debonding, adhesive remnant removal and polishing, on enamel surfaces.

\section{MATERIAL AND METHODS}

For this in vitro study, twelve bovine permanent incisors, stored in $0.1 \%$ thymol solution, ${ }^{4}$ were used. ${ }^{20}$

Verification of the existence of enamel cracks was performed by trans-ilumination of the buccal surface of teeth using fiber optic light ${ }^{10}$ and $1.2 \mathrm{X}$ magnifying lens. Only teeth with no enamel cracks or caries were selected.

Teeth were sectioned at the crown/root anatomic limit using a cutting machine and distilled water irrigation.

The crowns' buccal surfaces were regularized under copious water cooling with silicon carbide discs (320 and 600-grit) (Buehler, Lake Bluff, IL, USA). Polishing was performed with felt disks and $6 \mu$ diamond aqueous suspension (Buehler, Lake Bluff, IL, USA).

Crowns were embedded in acrylic resin blocks and stored in $0.1 \%$ thymol solution until brackets were bonded.

All instruments used were brand new exclusive for this research.

Specimens were divided into four groups $(n=3)$, according to the method used for brackets debonding and adhesive remnant removal (Table 1). The study outline, showing procedures, instruments used for brackets debonding, adhesive remnant removal and polishing, as well as the number of specimens in each group is represented in Figure 1.

Prophylaxis of enamel surface before bracket bonding was performed using a rubber cup (Microdont, Socorro, Brazil), ultra fine pumice powder (S.S. White, Rio de Janeiro, Brazil) and water at a lowspeed. Enamel surface was rinsed with water spray for 10 seconds and dried with compressed air for the same time. The center of enamel surface was then etched with $35 \%$ phosphoric acid gel (Scotchbond Etchant, 3M ESPE, St. Paul, MN, USA) for 15 seconds, rinsed with water spray for 10 seconds and dried with oil-free compressed air jets for 10 seconds. A fine and uniform layer of Transbond ${ }^{\mathrm{TM}}$ XT Primer-Adhesive (3M Unitek, Monrovia, CA, USA) was applied to the prepared 
Table 1 - Division of groups according to the instruments used for debonding and adhesive remnant removal and polishing, and the number of specimen for each group.
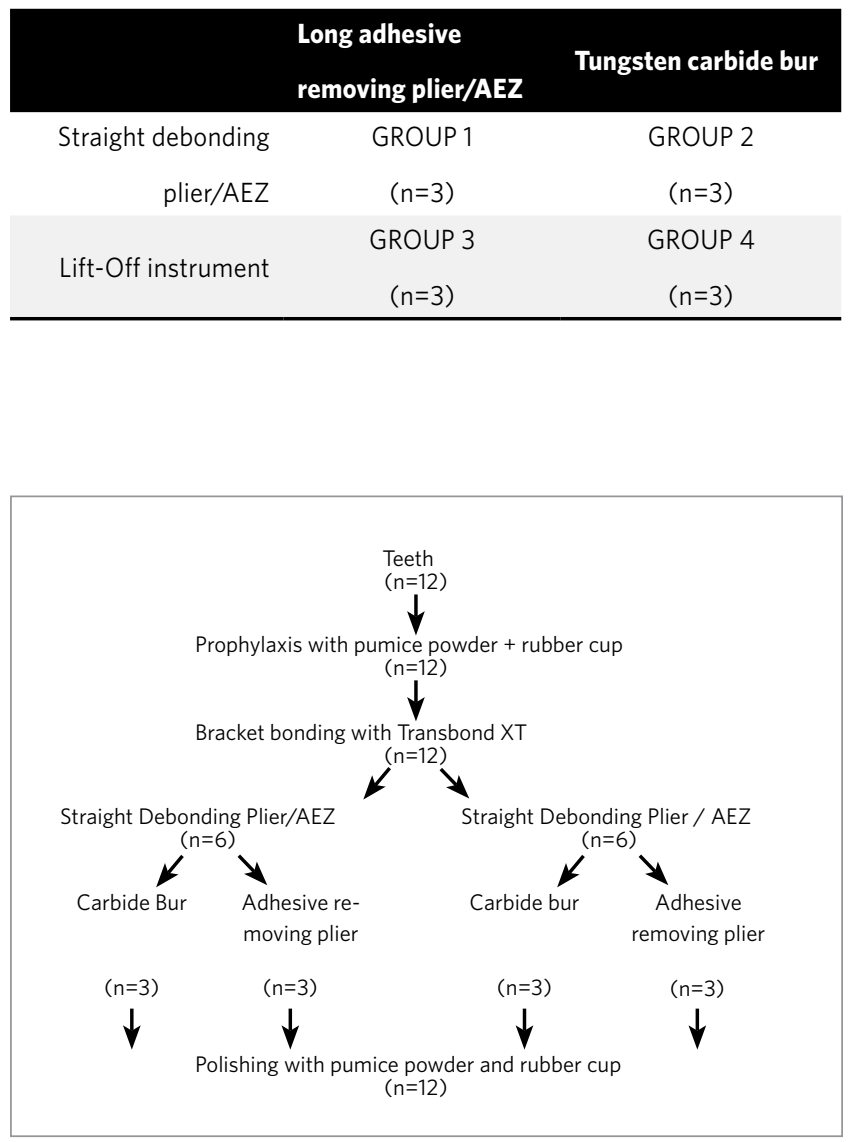

Figure 1 - Representative scheme of study outline showing procedures, instruments used bracket debonding, adhesive remnant removal and polishing, as well as the number of specimens in each group.

enamel surface with disposable microbrushes (Microbrush Corporation, Grafton, WI, USA) and spreaded with a short burst of moisture-free air blown.

Preadjusted stainless steel brackets for right maxillary central incisor (Kirium line, Abzil, São José do Rio Preto, Brazil) were positioned in the center of the crown long axis and bonded with Transbond ${ }^{\mathrm{TM}} \mathrm{XT}$ (3M Unitek) composite resin, receiving a perpendicular force of $300 \mathrm{~g}$, allowing excessive resin to flow off and producing a resin layer of similar thickness in all teeth. ${ }^{21}$ Bracket/enamel interface was light-cured (Ultralux, Dabi Atlante, Ribeirão Preto, Brazil) at a distance of $5 \mathrm{~mm}$ for 10 seconds at the mesial surface and 10 seconds at the distal surface.

Bracket debonding was performed 24 hours after bonding.
In groups 1 and 2 , brackets were removed using a straight debonding plier/AEZ (Ormco Corp., Glendora, CA, USA). The stainless steel blades of the plier were placed in the bracket/adhesive interface and a traction movement was performed.

In groups 3 and 4, brackets were debonded with the Lift-Off instrument (3M Unitek). The Lift-Off instrument has a metallic hook and a plastic pad. For debonding, the wire hook was placed in the right incisal tie-wing of the bracket and the plastic pad was placed on the crown's buccal surface, resulting in a traction force when activating the instrument.

After brackets debonding, in groups 1 and 3, the residual adhesive was removed with a long adhesive removing plier/AEZ (Ormco Corp.). The plastic interchangeable pad of the plier was placed on teeth's incisal edge and the active tip was used to remove remnant adhesive by compression. In groups 2 and 4 , residual adhesive was removed with a 12-blade tungsten carbide bur (\#7642, Jet Carbide Burs, Beavers Dental, Ontario, Canada) at high-speed with copious water cooling.

Removal of remnant adhesive was verified by visual inspection under a dental operating light and using the round tip of an exploratory probe, simulating a clinical exam.

In all groups, final polishing was performed using pumice, water and a rubber cup at low-speed for 30 seconds. The surfaces were washed for 10 seconds and dried with an air syringe for 10 seconds.

After debonding, removal of adhesive remnant and polishing, enamel surfaces were replicated in epoxy resin for SEM evaluation.

\section{Specimens preparation for SEM evaluation}

Teeth crown were rinsed with water, dried with compressed air and fixed in glass plates with utility wax. Crown buccal surfaces impressions were taken by applying a medium viscosity fluid paste (Express ${ }^{\mathrm{TM}}$ STD - 3M ESPE, St. Paul, MN, USA), followed by a thick paste (Express ${ }^{\mathrm{TM}}$ STD - 3M ESPE, St. Paul, MN, USA). After the impression paste was set, teeth were removed and low-viscosity epoxic resin (Buehler, Lake Bluff, IL, USA) was poured into impressions to prepare the enamel surface replicas. The replicas were then placed on metallic bases and gold coated. 


\section{SEM evaluation of enamel surface}

The scanning electron microscope (JSM T330A, JEOL, Tokyo, Japan) was used with an accelerating speed of $10 \mathrm{KV}$ at a working distance of $10 \mathrm{~mm}$. Each replica's image was magnified in 50X and 200X. Microscopic analysis was performed to evaluate enamel surface after debonding of brackets, removal of adhesive remnant and polishing, since these are the most critical stages regarding the occurrence of enamel damage. Images were stored in negative, digitized and then compared, considering similar magnifications.

Electron micrographs were evaluated by descriptive analysis. Images of groups 1, 2, 3 and 4 were selected to demonstrate typical appearance of enamel surface replicas in each stage.

\section{RESULTS}

Figure 2A shows the adhesive remnant on enamel surface after debonding with straight debonding plier in group 1 specimens. Removal of this residual adhesive with long adhesive removing plier caused enamel irregularities, vertical scratches and furrows (Fig 2B). Pumice polishing with rubber cup mitigated the scratches, remaining only the deepest furrows (Fig 2C).

In group 2, debonding was also made using the straight debonding plier, and some adhesive remained attached to enamel (Figure 3A). However, when adhesive removal was performed by tungsten carbide bur, enamel surface presented vertical and horizontal scratches (Fig 3B), which were mitigated after polishing with pumice and a rubber cup (Fig 3C).
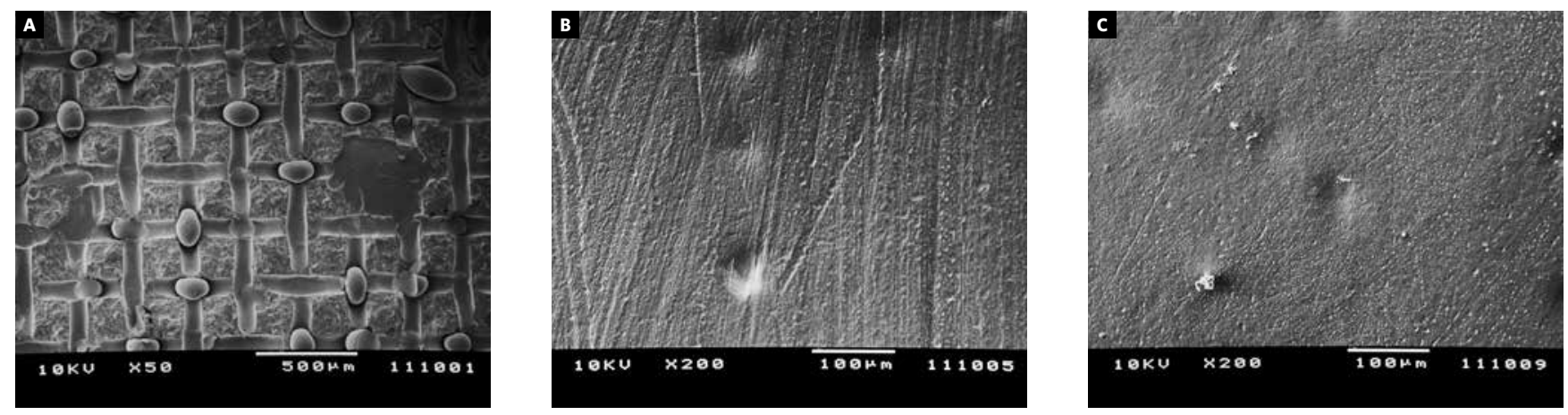

Figure 2 - Electron micrographs of group 1: A) debonding with straight debonding plier/AEZ (Ormco Corp.), B) removal of adhesive remnant with the long adhesive removing plier/AEZ (Ormco Corp.) and $\mathbf{C}$ ) after pumice polishing with rubber cup.
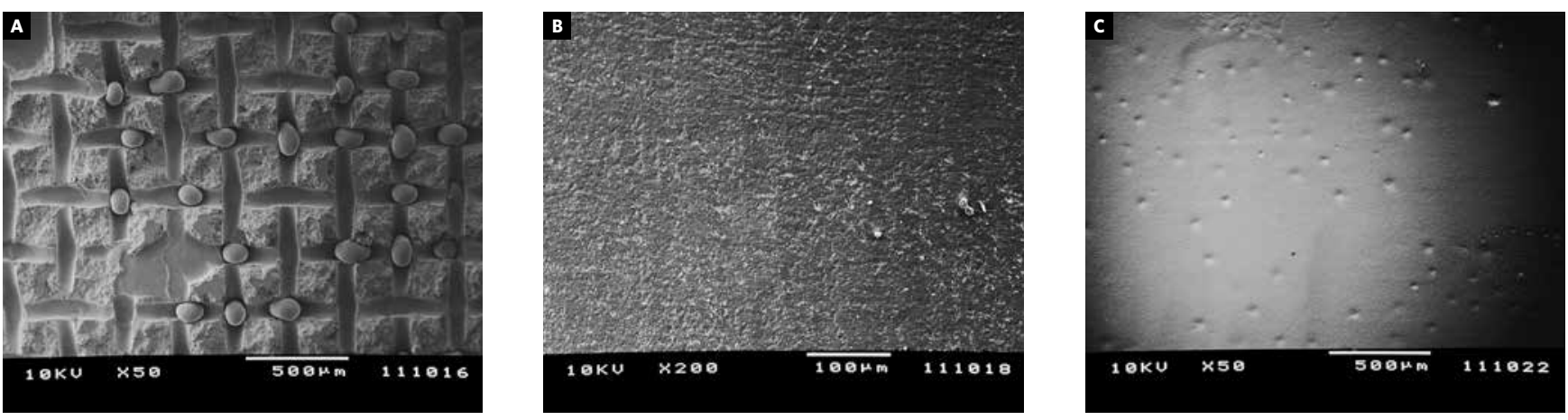

Figure 3 - Electron micrographs of group 2: A) debonding with straight debonding plier/AEZ (Ormco Corp.), B) removal of adhesive remnant with tungsten carbide bur (Beavers Dental) and $\mathbf{C}$ ) after pumice polishing with rubber cup. 
Figure 4A shows most part of adhesive remnant attached to enamel, after debonding with Lift-Off instrument, in group 3 specimens. Adhesive removal with long adhesive removing plier caused vertical scratches and furrows to enamel (Fig 4B). Pumice polishing with rubber cup mitigated the scratches, remaining only the deepest furrows, as presented on Figure $\mathrm{C}$.

In group 4, in which debonding was performed with Lift-Off instrument, some adhesive also remained attached to enamel surface (Fig 5A). When this remnant adhesive was removed with a tungsten carbide bur, surface presented horizontal scratches (Fig 5B), which were mitigated after polishing with pumice and a rubber cup (Fig 5C).

\section{DISCUSSION}

Despite the frequent use of human premolars in adhesion tests in orthodontics, ${ }^{22}$ the use of bovine teeth, especially permanent incisors, has become a viable alternative.

It is known that permanent and deciduous bovine enamel offers, respectively, $44 \%$ and $21 \%$ lesser resistance than human enamel. ${ }^{20}$ This difference is attributed to the fact that bovine teeth has a faster formation and development, presents more irregularities and also larger and wider enamel crystals. ${ }^{20}$

On the other hand, this disadvantage is outweighed by several advantages of the use of bovine enamel, such as: the structure of bovine enamel is similar to human enamel; it can be more easily obtained; simpler approval
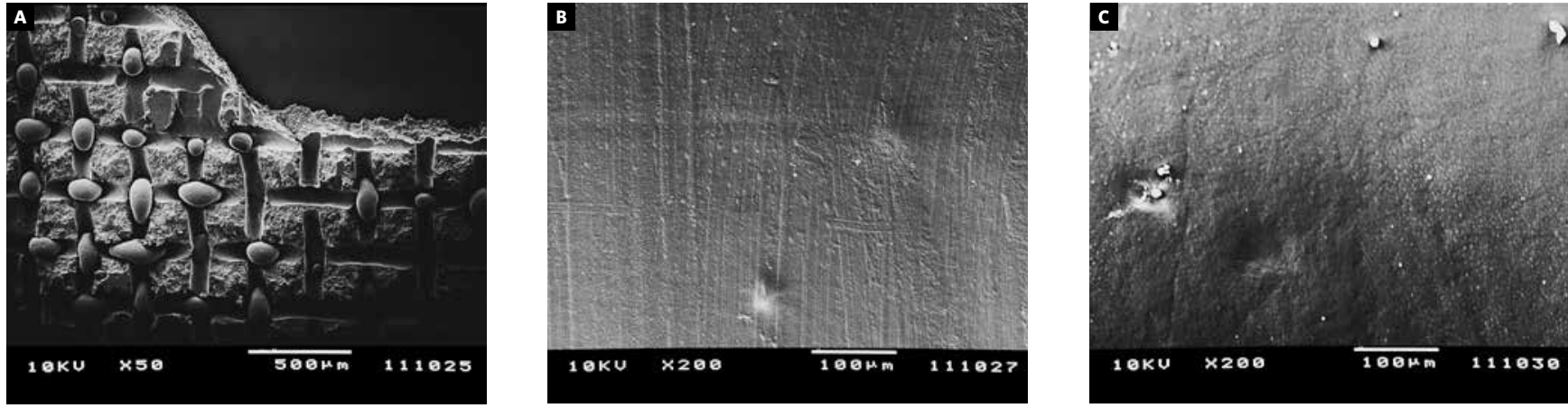

Figure 4 - Electron micrographs of group 3: A) debonding with the Lift-Off instrument (3M Unitek), B) removal of remnant adhesive with the long adhesive removing plier/AEZ (Ormco Corp.) and $\mathbf{C}$ ) after pumice polishing with rubber cup.
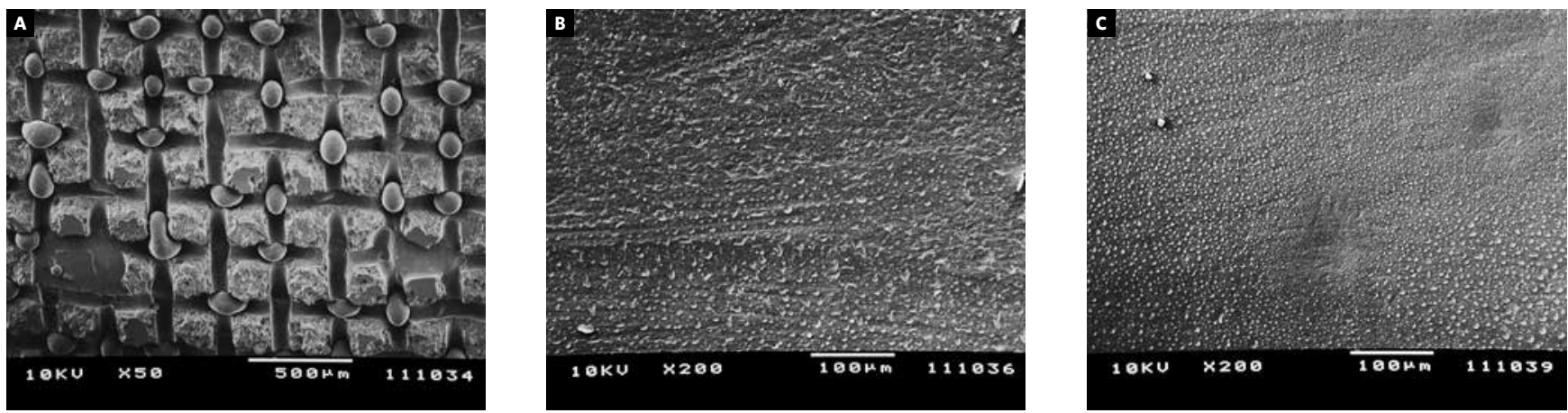

Figure 5 - Electron micrographs of group 4: A) debonding with the Lift-Off instrument (3M Unitek), B) removal of remnant adhesive with tungsten carbide bur (Beavers Dental) and $\mathbf{C}$ ) after pumice polishing with rubber cup. 
in Researches Ethics Committee; it is possible to standardize the substratum, minimizing variables in the tested hypothesis ; and its storage time. ${ }^{20}$

Metallic brackets was chosen because debonding of ceramic brackets increases the risk of fractures of these attachments ${ }^{23}$ and enamel scratches, ${ }^{24}$ making difficult the preservation of enamel surface structure at the end of orthodontic treatment.

Bonding system Transbond XT (3M Unitek) was chosen due to its great physical properties and wide clinical use, demonstrating satisfactory longitudinal result,s and also due to its greater bond strength when compared to other bonding systems. ${ }^{21,25}$

Bracket debonding was performed 24 hours after bonding, when the resin bonding systems achieve their maximum strength, with no statistically significant difference after longer periods. ${ }^{26}$

SEM evaluation is essential for observation of enamel morphological changes after different procedures for bracket debonding and surface polishing. 2,3,4,7,13,15-18

The use of epoxic resin replicas of the crown's buccal surface allows the study of the each sequential step of bonding and debonding brackets, reproducing with great reliability the clinical situation. ${ }^{7,13,27}$

There is still no safe way of debonding brackets jointly with the adhesive without the risk of enamel damage, because bonding systems are developed to increase bond strengths between enamel, adhesive and bracket. ${ }^{21}$

To this date, the concept of ideal debonding consists of failure in the bracket/adhesive interface, with adhesive remaining on enamel surface to be cautiously removed with adequate instruments, resulting in less enamel loss., ${ }^{4,22}$

The use of straight debonding plier produced a force concentration on the bracket/adhesive interface, and failure in this interface prevailed, since all resin remained attached to enamel in four specimens (Fig 2A and 3A).

When brackets were debonded with the Lift-Off instrument, force was concentrated in the tie wing of brackets. In 3 specimens there was failure in the bracket/adhesive interface (Fig 5A), with adhesive remaining in tooth surface; however, in other 3 specimens, resin was partially removed along with the bracket at debonding (Fig 4A).
These results diverge from the findings of Årtun and Bergland, ${ }^{28}$ Zarrinia, Eid and Kehoe ${ }^{5}$ and Oliver, ${ }^{12}$ which showed greater amount of resin attached to brackets when debonding was performed by applying force to the bracket base, instead the tie wings. This difference could be explained by the use of a different adhesive system. Knösel et $\mathrm{al}^{29}$ do not recommend the instrument Lift-Off (3M Unitek) for debonding brackets because they cause more damage to the enamel.

Tungsten carbide bur has been the most recommended instrument for removal of adhesive remnant, both at low ${ }^{5,7,9,11}$ and high speed. ${ }^{2,3,4,13,15}$ However, when comparing the use of this bur at both speeds, Rouleau, Grayson and Cooley ${ }^{13}$ and Eminkahyagil et al.15 verified best results at high-speed, while Ireland, Hossein \& Sherriff, ${ }^{9}$ found them at low-speed. The present work used the tungsten carbide bur at a high-speed with copious water cooling, because it is a fast procedure, ${ }^{15}$ and the water cooling prevent pulp damage. ${ }^{30}$

Removal of adhesive remnant with both the long adhesive removing plier and the 12 blades tungsten carbide bur showed to be efficient. However, these instruments produced some irregularities on enamel surface, as observed in Figures 2B, 3B, 4B and 5B.

The long adhesive removing plier caused vertical scratches, as shown in Figures 2B and 4B. This could have happened because the instrument is applied to the incisal edge of the tooth crown and its active tip is used to remove the remnant adhesive by compression.

Similarly to the reports of Retief and Denys, ${ }^{2}$ Gwinnett and Gorelick ${ }^{6}$ and Rouleau, Grayson and Cooley ${ }^{13}$ that manual instruments, like scoops and adhesive removing pliers, produce deep furrows that remain even after final polishing, the long adhesive removing plier can produce the same effects

The 12 blade tungsten carbide bur produced vertical scratches (Fig 3B), supposedly due to the disposition and number of blades of this instrument, and also horizontal scratches (Fig 3B and 5B), presumably caused during mesiodistal movement of the bur while removing the adhesive.

Retief and Denys, ${ }^{2}$ Waes, Matter and Krejci, ${ }^{11}$ Rouleau, Grayson and Cooley, ${ }^{13}$ Eminkahyagil et $\mathrm{al}^{15}$ and Ulosoy $^{31}$ also found scratches and furrows when using this bur, but reported that the adhesive remnant can be removed with minimal damage to enamel if the instrument was used carefully. 
Removal of all superficial adhesive remnant is essential, since its presence favors plaque accumulation, allowing the formation of decalcified areas and caries lesions. ${ }^{6}$ The residual adhesive can also be discolored by action of bacteria, food, cosmetic and chemical alterations of the bonding material, jeopardizing esthetics, one of the most important factors in orthodontic treatment. ${ }^{6}$

Considering that the procedures of debonding, adhesive remnant removal and final polishing can also remove some enamel tissue. ${ }^{11,19}$ they can cause changes in tooth morphology with formation of hollows and facets. ${ }^{19}$

Literature reports enamel loss varying from 27.5 to $48 \mu \mathrm{m}^{19}$ from 26.1 to $41.2 \mu \mathrm{m}^{8}$ and $55.6 \mu \mathrm{m}^{32}$, depending on the bonding system's filler characteristics, the instruments used, as well as on the measurement technique. This enamel loss is not clinically significant when compared to the average enamel thickness, which varies from 1500 to $2000 \mu \mathrm{m} .{ }^{19}$

Enamel loss during debonding procedures became clinically significant considering that the highest concentration of fluorides is located on the surface, and it declines significantly in the first $20 \mu \mathrm{m}$ of enamel. ${ }^{19}$ This way, the use of instruments and preservative techniques assumes great importance, because of the possibility of multiple bonding and treatments which could trespass this thickness.

Final polishing is considered an indispensable step to minimize enamel damage produced during debonding and adhesive remnant removal, ${ }^{2,3,4,6,7,16,18,19}$ as observed in Figures $2 \mathrm{C}$ and $5 \mathrm{C}$. The use of pumice, water and a rubber cup is the most suitable procedure because it removes less enamel when compared to bristle brushes. ${ }^{8,19}$

In the present work, it was observed that final polishing with pumice, water and a rubber cup minimized scratches and furrows, remaining only the deepest ones (Fig 2C, 3C, 4C and 5C), corroborating the results of Burapavong et al ${ }^{16}$ Rouleau, Grayson and Cooley ${ }^{13}$ and Vieira et $a l,{ }^{18}$ therefore, this procedure is indicated after using any adhesive removing instrument.

Enamel appearance after debonding and polishing should be compared to the adjacent surfaces. The clinical exam of enamel both dried and moistened is important because of reflection and refraction phenomena related to the moistened surface that can mask some irregularities. ${ }^{6}$

Among all aspects evaluated in the present study, it is advisable to use an ideal sequence of clinical steps when debonding brackets, aiming at less damage to enamel surface and at clinical feasibility under actual conditions.

\section{CONCLUSION}

All four protocols for bracket debonding, removal of adhesive remnant and polishing caused enamel irregularities.

Brackets debonding using the straight debonding plier, followed by removal of residual adhesive with tungsten carbide bur at high-speed and water cooling, and polishing with pumice and a rubber cup showed to be the protocol that caused the least damage to enamel, and therefore, it is the suggested debonding protocol. 


\section{REFERENCES}

1. Buonocore MG. A simple method of increasing the adhesion of acrylic filling materials to enamel surfaces. J Dent Res. 1955;34:849-53.

2. Retief $D H$, Denys FR. Finishing of enamel surfaces after debonding of orthodontic attachments. Angle Orthod. 1979;49:1-10.

3. Campbell PM. Enamel surfaces after orthodontic bracket debonding. Angle Orthod. 1995;65:103-10.

4. Zarrinia K, Eid NM, Kehoe MJ. The effect of different debonding techniques on the enamel surface: an in vitro qualitative study. Am J Orthod Dentofac Orthop. 1995;108:284-93.

5. Hosein I, Sherriff M, Irland AJ. Enamel loss during bonding, debonding, and cleanup with use of a self-etching primer. Am J Orthod Dentofac Orthop. 2004;126:717-24.

6. Gwinnett AJ, Gorelick L. Microscopic evaluation of enamel after debonding: clinical application. Am J Orthod. 1977;71:651-65

7. Zachrisson BU, Årtun J. Enamel surface appearance after various debonding techniques. Am J Orthod. 1979;75:121-37.

8. Pus MD, Way DC. Enamel loss due to orthodontic bonding with filled and unfilled resins using various clean-up techniques. Am J Orthod. 1980;77:269-83.

9. Ireland AJ, Hosein I, Sherriff M. Enamel loss at bond and clean-up following the use of a conventional light-cured composite and a resin-modified glass polyalkenoate cement. Eur J Orthod. 2005;27:413-9.

10. Zachrisson BU, Skogan O, Höymyhr S. Enamel cracks in debonded, debanded, and orthodontically untreated teeth. Am J Orthod. 1980;77:307-19.

11. Waes H, Matter T, Krejci I. Three-dimensional measurement of enamel loss caused by bonding and debonding of orthodontic brackets. Am J Orthod Dentofac Orthop 1997;112:666-9

12. Oliver RG. The effect of different methods of bracket removal on the amount of residual adhesive. Am J Orthod Dentofac Orthop. 1988;93:196-200.

13. Rouleau BD, Grayson WM, Cooley RO. Enamel surface evaluations after clinical treatment and removal of orthodontic brackets. Am J Orthod. 1982:81:423-6.

14. Katona TR. Stresses developed during clinical debonding of stainless steel orthodontic brackets. Angle Orthod. 1997;67:39-46.

15. Eminkahyagil N, Arman A, Çetinsahin A, Karabulut E. Effect of resin-removal methods on enamel and shear bond strength of rebounded brackets. Angle Orthod. 2006;76:314-21.

16. Burapavong V, Marshall GW, Apfel DA, Perry HT. Enamel surface characteristics on removal of bonded orthodontic brackets. Am J Orthod. 1978;74:176-87.

17. Tüfekçi E, Merrill TE, Pintado MR, Beyer JP, Brantley WA. Enamel loss associated with orthodontic adhesive removal on teeth with white spot lesions: an in vitro study. Am J Orthod Dentofac Orthop. 2004;125:733-40.
18. Vieira $\mathrm{ACL}$, Pinto RAC, Chevitarese $\mathrm{O}$, Almeida MA. Polishing after debracketing: its influence upon enamel surface. J Clin Pediatr Dent. 1993; 18:7-11.

19. Brown CRL, Way DC. Enamel loss during orthodontic bonding and subsequent loss during removal of filled and unfilled adhesives. Am J Orthod. 1978;74:663-71.

20. Osterle LJ, Shellhart WC, Belanger GK. The use of bovine enamel in bonding studies. Am J Orthod Dentofac Orthop. 1998;114:514-9.

21. Bishara SE, Ajlouni R, Laffoon J, Warren J. Effects of modifying the adhesive composition on the bond strength of orthodontic brackets. Angle Orthod. 2002:72:464-7.

22. Fox NA, McCabe JF, Buckley JG. A critique of bond strength testing in orthodontics. Br J Orthod. 1994;21:33-43.

23. Liu JK, Chung $\mathrm{CH}$, Chang $\mathrm{CY}$, Shieh DB. Bond strength and debonding characteristics of a new ceramic bracket. Am J Orthod Dentofacial Orthop. 2005;128:761-5.

24. Bishara SE, Fonseca JM, Boyer DB. The use of debonding pliers in the removal of ceramic brackets: force levels and enamel cracks. Am J Orthod Dentofacial Orthop. 1995;108:242-8

25. Owens SE Jr, Miller BH. A comparison of shear bond strengths of three visible light-cured orthodontic adhesives. Angle Orthod. 2000;70:352-6.

26. Chanda RA, Stein E. Time-related bond strength of light-cured and chemically cured bonding systems: an in vitro study. Am Orthod Dentofacial Orthop. 1996;110:378-82

27. Wilner FJ, Oliver GR. Evaluation of a reproduction technique for the study of the enamel composite/bracket base area. J Orthod. 2000;27:261-6.

28. Årtun J, Bergland S. Clinical trials with crystal growth conditioning as an alternative two acid-etch enamel pretreatment. Am J Orthod. 1984;85:333-340.

29. Knösel M, Mattysek S, Jung K, Sadat-Khonsari R, Kubein-Meesenburg D, Bauss $\mathrm{O}$, Ziebolz D. Impulse debracketing compared to conventional debonding. Angle Orthod. 2010;80(6):1036-44.

30. Uysal T, Eldeniz AU, Usumez S, Usumez A. Thermal changes in the pulp chamber during different adhesive clean-up procedures. Angle Orthod. 2005;75:216-21.

31. Ulosoy C. Comparison of finishing and polishing systems for residual resin removal after debonding. J Appl Oral Sci. 2009;17(3):209-15.

32. Fitzpatrick DA, Way DC. The effects of wear, acid etching, and bond removal on human enamel. Am J Orthod. 1977;72:671-81. 